\title{
miR-148a downregulates the expression of transforming growth factor- $\beta 2$ and SMAD2 in gastric cancer
}

\author{
WEI ZHANG and YAN LI \\ Department of Oncology, Zhongnan Hospital of Wuhan University, Wuhan, Hubei 430071, P.R. China
}

Received December 19, 2015; Accepted February 18, 2016

DOI: 10.3892/ijo.2016.3437

\begin{abstract}
The effects of miR-148a in regulating the expression of TGF $\beta 2$ and SMAD2 in MNNG-initiated gastric cancer rats and the mechanism of action in GC cells were determined. Effects of miR-148a on the proliferation, migration, and invasion of GC cell lines were demonstrated. We used Wistar rats, Balb/c nude mice, and GC cell lines. Rats were treated with MNNG to establish a GC rat model. Levels of miR-148a, TGF $\alpha$, TGFß2, SMAD2, SMAD3, and SMAD4 were tested in gastric tissues from different groups. In GC cell lines, we constructed and transfected a primary miR-148a plasmid to determine the expression patterns of TGF $\beta 2$, SMAD2, and SMAD4. A luciferase activity assay was used to monitor the effects of miR-148a on the TGF 32 - and SMAD2-3'UTRs. We identified nude mouse models bearing BGC-823-miR-148a or BGC-823-vector cells. Tumor volumes were detected, and TGF $\beta 2$, SMAD2 expression levels were determined in tumor tissues. The in vivo study demonstrated an increase in the mRNA and protein levels of TGF $\beta 2$, SMAD2, and SMAD4 in the MNNG-treated group compared with the control group. However, there were no differences in the mRNA and protein levels in either TGF $\alpha$ or SMAD3. The in vitro study demonstrated that overexpression of miR-148a reduced TGF $\beta 2$ and SMAD2 significantly in GC cells. The results of the luciferase activity assay showed that miR-148a could bind to the 3'UTRs of TGF 32 and SMAD2 and inhibited their activity. Overexpression of miR-148a inhibited proliferation, migration, and invasion significantly in GC cell lines. In vivo,
\end{abstract}

Correspondence to: Dr Yan Li, Department of Oncology, Zhongnan Hospital of Wuhan University, 185 Donghu Road, Wuhan, Hubei 430071, P.R. China

E-mail: yanliwhu@126.com

Abbreviations: TGF $\alpha$, transforming growth factor $\alpha$; GC, gastric cancer; TGF $\beta 2$, transforming growth factor- $\beta 2$; MNNG, N-methylN9-nitro-N-nitrosoguanidine; DMEM, Dulbecco's modified Eagle's medium; UTR, untranslated region; M-MLV, moloney murine leukemia virus reverse transcriptase; miR, microRNA

Key words: gastric cancer, microRNA-148a, transforming growth factor- $\beta 2$, Drosophila mothers against decapentaplegic 2 , SMAD2 tumor volume of BGC-823-miR-148a was smaller than that of BGC-823-vector. Overall, miR-148a inhibited the proliferation, migration, invasion, and expression of TGF $\beta 2$ and SMAD2 in GC cells. It was concluded that miR-148a might play an important role in gastric cancer, and is a potential candidate for GC treatment.

\section{Introduction}

Gastric cancer (GC) remains a major health problem and is a leading cause of morbidity and mortality worldwide, representing the second most common cause of cancer-related deaths (1). In 2012, GC caused 723,000 new deaths in the world (2) because of its poor prognosis and the limited efficacy of the treatment. It is widely accepted that environmental factors, such as Helicobacter pylori infections (3), EpsteinBarr viruses, diet, smoking and obesity, contribute to gastric carcinogenesis (4). Additionally, genetic factors have been implicated in GC development, including somatic mutations, gene amplifications and deletions, epigenetic inactivation of several genes, and aberrant DNA methylation $(5,6)$. Molecular profiling of GCs has been performed using gene expression or DNA sequencing, which has facilitated the identification of putative biomarkers for subtype classification, prognosis and therapeutic targets (7-9). However, the molecular mechanisms underlying the progression of gastric carcinoma are still poorly understood. Besides protein coding genes, recent evidence has shown that there is an important role for microRNAs (miRs) in human cancers (10). miRs are short ( 22 nucleotides), non-coding RNAs that regulate gene expression primarily by translational repression or transcriptional degradation, and are involved in cellular processes such as cell proliferation, cell death, and tumorigenesis (11-13). Studies have suggested that there are oncogenic and tumor suppressive roles for miRs in cancers $(14,15)$. miRs have great potential as cancer biomarkers in terms of their tissue-specific expression and aberrant expression in cancer cells (16) based on data from high-throughput microarray analysis. In GC, aberrant miR expression profiles have been associated with GC progression, prognosis $(17,18)$ and pathogenesis by perturbing the function of its target genes (19-22).

miR-148a is one of the most significantly downregulated miRs in GC cell lines, GC tissue samples, and in GC patients compared with adjacent normal gastric tissues (23-25). Therefore, the aberrant expression of miR-148a suggests that 
it may be involved in GC progression. In this study, we used MNNG (N-methyl-N9-nitroN-nitrosoguanidine) treatment to establish a rat GC model, and used the human GC cell lines AGS, YCC3 and BGC-823 to investigate the effects of miR148a on the development and progression of GC.

\section{Material and methods}

Animals. Forty-four one-week-old, grade 3, male Wistar rats (approximately $50 \mathrm{~g}$ in weight) were supplied by the Experimental Animal Center (Hubei, China) and kept in a room under a $12 \mathrm{~h}$ artificial light/dark cycle with free access to food and water. Acclimatization period of one week was observed prior to the initiation of experimentation. The procedures were approved by the Animal Care Committee of Wuhan University and complied with the recommendations of the Chinese guidelines for the care and use of laboratory animals.

Cell culture. GC cell lines (AGS, YCC3, SCH and BGC-823 cells) were grown in DMEM (Hyclone, HyClone Laboratories, Logan, UT, USA) containing $10 \%$ fetal bovine serum (FBS; Gibco, Waltham, MA, USA), $100 \mathrm{U} / \mathrm{ml}$ penicillin, and $100 \mu \mathrm{g} / \mathrm{ml}$ streptomycin at $37^{\circ} \mathrm{C}$ in a humidified chamber. YCC3 and SCH cells were maintained in Roswell Park Memorial Institute medium (RPMI-1640; Hyclone, HyClone Laboratories) containing $10 \% \mathrm{FBS}, 100 \mathrm{U} / \mathrm{ml}$ penicillin and $100 \mu \mathrm{g} / \mathrm{ml}$ streptomycin at $37^{\circ} \mathrm{C}$ in a humidified chamber.

Drug treatments. MNNG (Fluka, Germany) solution was prepared three times per week with distilled water at a concentration of $100 \mathrm{mg} / \mathrm{ml}$. The solution was protected from light and given ad libitum to the animals in their drinking water. In addition to MNNG, all animals were given $1 \mathrm{ml}$ of $10 \%$ sodium chloride weekly by oral gavage in the initial six weeks of the study to enhance GC development. MNNG and control PBS were administered by oral gavage daily from the age of six weeks for a total of 40 weeks.

Plasmid construction and transfection. The fragments encoding primary miRs were cloned into the pcDNA-3.1(-) vector (Invitrogen; Carlsbad, CA, USA) following digestion with Xhol/BamHI (Thermo Scientific; Waltham, MA, USA). The forward and reverse primers for the human primary miR-148a (pri-miR-148a) are listed in Table I. To construct the luciferase reporter plasmids, the 3'-UTR sequences from $+2,286$ to $+2,308$ of TGF $\beta 2$ and sequence from $+8,335$ to $+8,357$ of SMAD2 were inserted at the HindIII/XhoI site downstream of the luciferase gene in the pGL3-promoter vector. All final constructs were verified by DNA sequence analysis.

Real-time quantitative reverse transcriptase PCR. Gastric tissues and total cellular RNA was isolated using TRIzol reagent (Invitrogen) according to the manufacturer's protocol. RNA $(1 \mu \mathrm{g})$ was reverse transcribed into cDNA using dNTPs $(1 \mathrm{mM}), 5 \mathrm{X}$ reverse transcription buffer $(500 \mathrm{mM}$ Tris- $\mathrm{HCl}$, pH 8.3, $250 \mathrm{mM} \mathrm{KCl}, 50 \mathrm{mM} \mathrm{MgCl}{ }_{2}$, and $50 \mathrm{mM} \mathrm{DTT}$ ), 16 units RNasin, and 2.5 units of M-MLV reverse transcriptase (Promega; Madison, WI, USA). SYBR Green (Toyobo; Osaka, Japan) was used for all real-time PCR reactions. All real-time PCR reactions were performed and analyzed with the CFX connect real-time PCR detection system (Bio-Rad; Hercules, CA, USA). The primers and PCR conditions for miR-148a, human and rat TGF $\alpha$, TGF 32 , SMAD2, SMAD3 and SMAD4 are listed in Table I. GAPDH was used to normalize the relative expression levels of TGF $\alpha$, TGF $\beta 2$, SMAD2, SMAD3 and SMAD4. U6 was used to normalize the relative expression levels of miRs. Gene expression levels were calculated using the $2^{-\Delta \Delta \mathrm{CT}}$ method relative to the internal control.

Transient transfection and luciferase assays. GC cell lines (AGS, YCC3 and $\mathrm{SCH}$ ) were used for the luciferase assays. Cells were transiently co-transfected with pcDNA-3.1(-) expression vectors or with an empty pGL-3 vector. A dualluciferase reporter assay system was used according to the manufacturer's instructions (Promega). Luciferase activity was quantified $48 \mathrm{~h}$ after transfection using a luminometer and the Stop \& GloH Dual Luciferase kit (Promega). To control for transfection efficiency, firefly luciferase activity was corrected according to Renilla luciferase activity.

Western blotting. Western blots were used to detect the protein levels in different rat groups. Briefly, the tissues of the control and GC groups were weighed and homogenized with an ultrasound homogenizer and gastric tissues were subsequently lysed in lysis buffer ( $1 \mathrm{ml}$ of $1 \% \mathrm{NP}-40,25 \mathrm{mM}$ Tris-HCl, $150 \mathrm{mM} \mathrm{NaCl}, 10 \mathrm{mM}$ EDTA, pH 8.0, containing a $2.5 \%$ protease inhibitor cocktail P2714 (Sigma, St. Louis, MO, USA) for $30 \mathrm{~min}$ on ice. Samples were centrifuged at $14,000 \mathrm{x} \mathrm{g}$ for $15 \mathrm{~min}$. To detect the TGF $\alpha$, TGF 32 , SMAD2, SMAD3 and SMAD4 proteins, the proteins $(30 \mu \mathrm{g})$ were separated by SDS-polyacrylamide gel electrophoresis. The membranes were incubated for $2 \mathrm{~h}$ with a monoclonal mouse anti-human TGF $\alpha$ antibody (1:1500, Santa Cruz Biotechnology; Santa Cruz, CA, USA), a polyclonal rabbit anti-human TGF $\beta 2$ antibody (1:2000, Millipore; Billerica, MA, USA), or a polyclonal goat anti-human SMAD2 and SMAD4 (1:1500, Santa Cruz Biotechnology). All of the blots were incubated with a peroxidase-conjugated secondary antibody (1:6000, Millipore) for $1 \mathrm{~h}$. $\beta$-actin was used as an internal control. The blots were then developed using the ECL detection kit (Thermo Scientific) to produce a chemiluminescent signal that was captured on X-ray film.

Immunofluorescence cytochemistry. The GC cell line AGS was washed twice with cold-PBS and then fixed with $4 \%$ paraformaldehyde for $10 \mathrm{~min}$, permeabilized and blocked with $0.1 \%$ Triton X-100 and $1 \%$ BSA for $10 \mathrm{~min}$. The cells were incubated with a polyclonal rabbit anti-human TGF $\beta 2$ antibody (1:100, Millipore) or a polyclonal goat anti-human SMAD2 antibody (1:100, Santa Cruz Biotechnology) overnight at $4^{\circ} \mathrm{C}$ and then incubated with DYLight 549 (1:100, Boster Biological Technology; Wuhan, China) in $1 \%$ BSA for $1.5 \mathrm{~h}$ at $37^{\circ} \mathrm{C}$. After being washed three-times with ice-cold PBS, the cells were incubated with DAPI for $10 \mathrm{~min}$. The images were captured and analyzed using fluorescence microscopy (Olympus Corp., Tokyo, Japan).

Cell proliferation, migration, and invasion assays. All experiments were performed according to the manufacturer's instructions. Briefly, cell proliferation assays were performed 
Table I. Primer sequences used for real-time RT-PCR.

\begin{tabular}{|c|c|c|c|c|}
\hline Gene & Forward/Reverse & Primer (5'-3') & $\operatorname{Tm}\left({ }^{\circ} \mathrm{C}\right)$ & Cycles \\
\hline hTGF $\beta 2$ & $\begin{array}{l}\text { Forward } \\
\text { Reverse }\end{array}$ & $\begin{array}{l}\text { TGGTGAAAGCAGAGTTCAGAG } \\
\text { CACAACTTTGCTGTCGATGTAG }\end{array}$ & 60 & 40 \\
\hline hSMAD2 & $\begin{array}{l}\text { Forward } \\
\text { Reverse }\end{array}$ & $\begin{array}{l}\text { AAGCAGTGAAAAGTCTGGTG } \\
\text { GTTGTATCCCACTGATCTAT }\end{array}$ & 60 & 40 \\
\hline hSMAD4 & $\begin{array}{l}\text { Forward } \\
\text { Reverse }\end{array}$ & $\begin{array}{l}\text { TGGGAAGAGATCACCCTGTC } \\
\text { CCCAACGGTAAAAGACCTCA }\end{array}$ & 60 & 40 \\
\hline hGAPDH & $\begin{array}{l}\text { Forward } \\
\text { Reverse }\end{array}$ & $\begin{array}{l}\text { GAGTCAACGGATTTGGTCGT } \\
\text { AATGAAGGGGTCATTGATGG }\end{array}$ & 60 & 40 \\
\hline rTGF $\alpha$ & $\begin{array}{l}\text { Forward } \\
\text { Reverse }\end{array}$ & $\begin{array}{l}\text { GTATCCTGGTAGCTGTGTGT } \\
\text { ATACTGAGTGTGGGAATCTGGG }\end{array}$ & 60 & 40 \\
\hline rTGF $\beta 2$ & $\begin{array}{l}\text { Forward } \\
\text { Reverse }\end{array}$ & $\begin{array}{l}\text { CATGCCCTTATCTGTGGAGTTC } \\
\text { TGGGCGTATTGCCAATGT }\end{array}$ & 60 & 40 \\
\hline rSMAD2 & $\begin{array}{l}\text { Forward } \\
\text { Reverse }\end{array}$ & $\begin{array}{l}\text { AGCAGTGAAAAGTCTGGTGA } \\
\text { AGAGCAAGTGCTTGGTATGG }\end{array}$ & 60 & 40 \\
\hline rSMAD3 & $\begin{array}{l}\text { Forward } \\
\text { Reverse }\end{array}$ & $\begin{array}{l}\text { CAGAACGTGAACACCAAGT } \\
\text { CAAGCGGCAGTAGATGAC }\end{array}$ & 60 & 40 \\
\hline rSMAD4 & $\begin{array}{l}\text { Forward } \\
\text { Reverse }\end{array}$ & $\begin{array}{l}\text { CGCCTGTCTGAGCA TTGTAC } \\
\text { CGATTACTTGGTGGATGTTGG }\end{array}$ & 60 & 40 \\
\hline rGAPDH & $\begin{array}{l}\text { Forward } \\
\text { Reverse }\end{array}$ & $\begin{array}{l}\text { TGACTCTACCCACGGCAAGTTCAA } \\
\text { ACGACATACTCAGCACCAGCATCA }\end{array}$ & 60 & 40 \\
\hline miR-148a & & GTCGTATCCAGTGCGTGTCGTGGA & & \\
\hline RT & & $\begin{array}{l}\text { GTCGGCAATTGCACTGGATACGAC } \\
\text { ACAAAG }\end{array}$ & & \\
\hline $\operatorname{miR}-148 \mathrm{a}$ & $\begin{array}{l}\text { Forward } \\
\text { Reverse }\end{array}$ & $\begin{array}{l}\text { GTTCCATTATCGGTCGCAT } \\
\text { TCTACAGTCAGGAGTCCACC }\end{array}$ & 60 & 40 \\
\hline U6 & $\begin{array}{l}\text { Forward } \\
\text { Reverse }\end{array}$ & $\begin{array}{l}\text { CTCGCTTCGGCAGCACA } \\
\text { AACGCTTCACGAATTTGCGT }\end{array}$ & 60 & 40 \\
\hline pcDNA3.1-miR-148a & $\begin{array}{l}\text { Forward } \\
\text { Reverse }\end{array}$ & $\begin{array}{l}\text { CCTCGAGGTTCCATTATCGGTCGCAT } \\
\text { CGGGATCCACCAGGGTAAGATGAAGAGA }\end{array}$ & & \\
\hline
\end{tabular}

Restriction enzyme sites appear underlined.

using a Cell Titer 96 Aqueous non-radioactive Cell Proliferation Assay kit (Promega) and measured using a Perkin Elmer plate reader (EnVision ${ }^{\mathrm{TM}}$ Multilabel Plate Reader). Triplicate assays were performed. Colony formation assay was used to further study the effect of miR-148a on cell proliferation. Three cells were plated in 6-well plates and cultured for 10 days. Colonies were fixed with $10 \%$ formaldehyde for $5 \mathrm{~min}$ and stained with $1.0 \%$ crystal violet for $30 \mathrm{sec}$.

Cell migration assays were performed using BioCoat ${ }^{\mathrm{TM}}$ 24-well chambers with $8-\mu$ m pore filter inserts (BDBiosciences, San Diego, CA, USA). After chamber rehydration, $5 \times 10^{4}$ cells were transferred to the upper chamber in $500 \mu \mathrm{l}$ of serumfree medium. Complete medium with $10 \%$ FBS was used as a chemoattractant. Cells were incubated for $48 \mathrm{~h}$, and the migrated cells on the lower surface of the insert or in the wells were trypsinized so that cell numbers could be quantified. Each assay was performed in triplicate, and the results were averaged over three independent experiments.

Cell invasion assays were performed similarly using BioCoat Matrigel ${ }^{\mathrm{TM}}$ invasion chambers with $8-\mu \mathrm{m}$ pore polycarbonate membranes that were precoated with Matrigel Matrix (BD Biosciences).

Tumor growth in nude mice. An equal number $\left(1 \times 10^{7}\right)$ of BGC-823 cells transfected with pcDNA-3.1-miR-148a or pcDNA-3.1 were harvested after $72 \mathrm{~h}$. Three groups (each group with six mice) of four- to six-week-old male Balb/c nude mice were given subcutaneous injections with BGC-823-miR148a cells or BGC-vector cells. The mice were monitored every three days for tumor formation. The tumor sizes were 


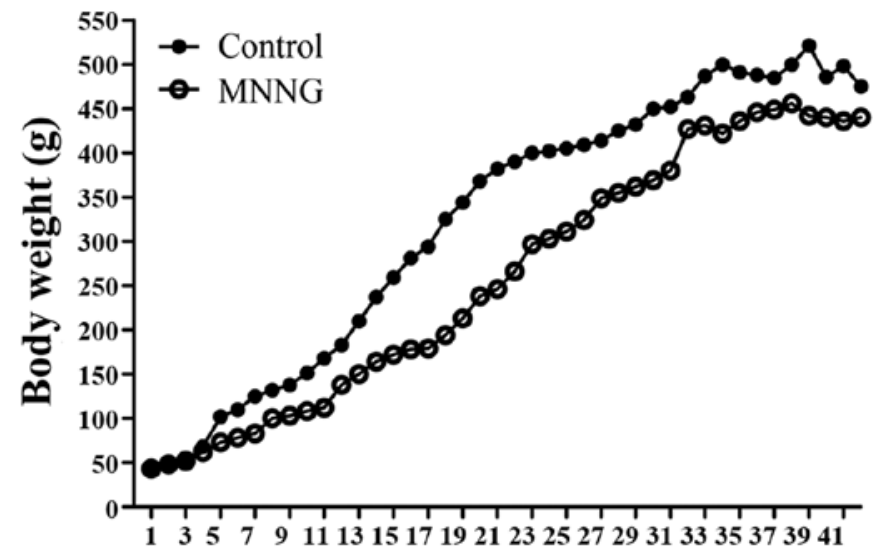

Figure 1. The body weights of animals in the MNNG-treatment and control groups. The body weights in different groups were measured weekly during the whole study period. The results indicate that weights of control group rats were higher than the MNNG-treated groups during the whole study period. n=20 (control), and n=15 (MNNG).

measured every three days using calipers. The tumor size at 31 days post-injection was used as the endpoint reading. The data are presented as the mean volume mean \pm SD. TGF $\beta 2$ and SMAD2 proteins in tumors were detected by qPCR.

Flow cytometry assay. BGC-823-miR-148a cells or BGC-vector cells were isolated and made into single cell suspensions, washed with PBS and then fixed in $3 \mathrm{ml}$ cold $70 \%$ ethanol for $1 \mathrm{~h}$ at $-20^{\circ} \mathrm{C}$. The cells were then washed three times with BioLegend Cell Staining Buffer and resuspended in $100 \mu \mathrm{l}$ of PBS. APC-conjugated Ki-67 antibody $(10 \mu 1$, BioLegend) was added and incubated at room temperature in the dark for $30 \mathrm{~min}$. Cells were washed with BioLegend Cell Staining Buffer and then resuspended in $0.5 \mathrm{ml}$ of PBS for flow cytometric analysis.

Statistical analyses. The results were expressed as the mean \pm SD. Statistical analyses were performed using one-way
Table II. Tumor incidence and the cause of death in the groups of study animals.

\begin{tabular}{lcc}
\hline Group & Control & MNNG \\
\hline $\begin{array}{l}\text { No. of rats } \\
\text { No. of death (\%) }\end{array}$ & $0(0)$ & 20 \\
Cause of death & $5(25)$ & $\begin{array}{l}\text { Gastric cancer (3), small bowel } \\
\text { cancer (1), unknown (1) }\end{array}$ \\
$\begin{array}{l}\text { No. of rats with } \\
\text { gastric tumors (\%) }\end{array}$ & $0(0)$ & $180)$ \\
\hline
\end{tabular}

ANOVAs followed by least significant difference (LSD) posthoc tests, with a p-value $<0.05$ being considered to indicate a statistically significant difference.

\section{Results}

$M N N G$-induced gastric cancer in rats. To determine the effects of the MNNG-initiated GC rat model, all animals were monitored closely for general health during the study period and their body weights were recorded weekly. The results demonstrated that the body weights of the control animals were higher than that in the MNNG-treated group throughout the study. In the early phase of the study (from the 14th-31st week), the differences in body weights between the control and MNNG-treated groups were significant (Fig. 1). There were a total of five deaths during this study period: none in the control group and five in the MNNG-treated group. The causes of death are listed in Table II. The incidence of MNNG-initiated GC are shown in Table II.

$M N N G$ increases TGF $\beta 2$, SMAD2, and SMAD4 in rat gastric tissues. The mRNA and protein levels of TGF $\beta 2$ were 2.1-fold and 2.1-fold higher in the MNNG-treated group compared

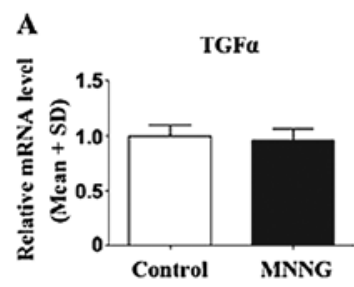

$\mathbf{F}$
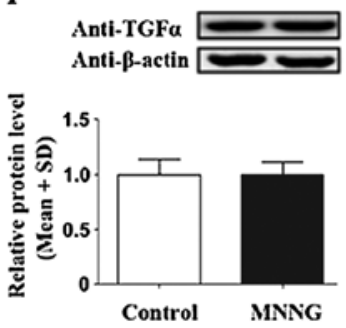

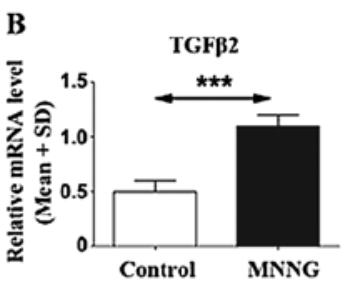

G
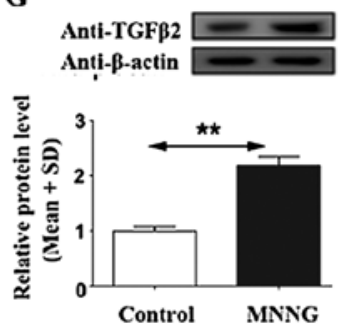

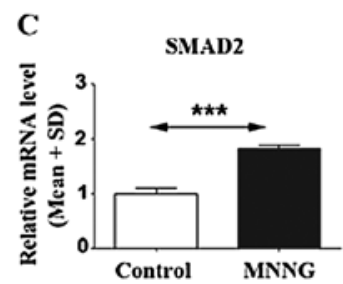

H

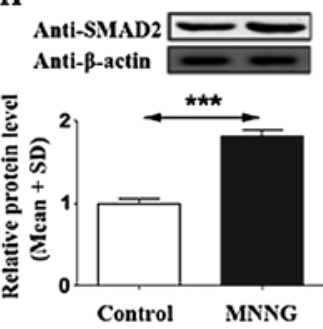

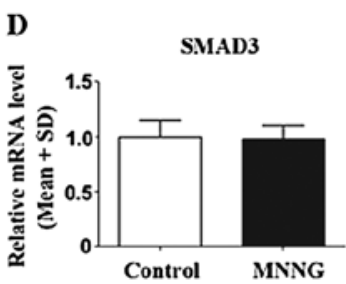

I

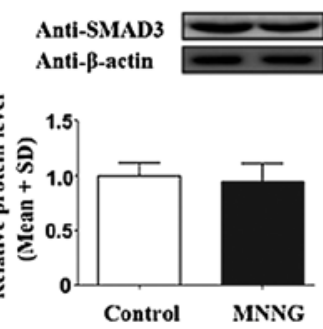

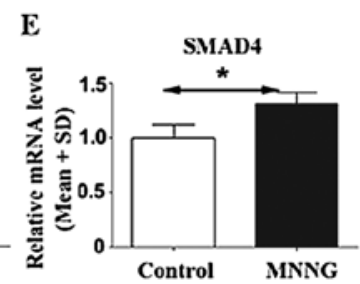

J
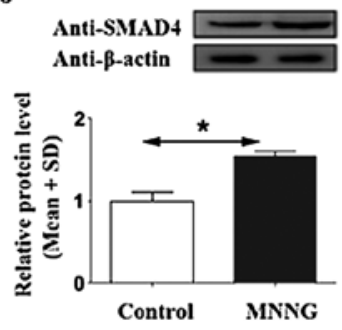

Figure 2. Changes in TGF $\alpha$, TGF 32 , SMAD2, SMAD3, and SMAD4 in MNNG-treated rats. MNNG induced TGF 32 , SMAD2, and SMAD4 mRNA levels (B, C and E) and protein levels (G, H and J), but did not affect TGF $\alpha$ and SMAD3 mRNA levels (A and E) and protein levels (F and I). The upper part shows mRNA levels in different groups (A-E), and lower part shows protein levels by western blotting. A representative immunoblot is shown. $\beta$-actin was used as a loading control (F-J). $\mathrm{n}=20$ (control), and $\mathrm{n}=15$ (MNNG). ${ }^{*} \mathrm{p}<0.05,{ }^{* *} \mathrm{p}<0.01$ and ${ }^{* * * *} \mathrm{p}<0.001$ vs. the control. 
A

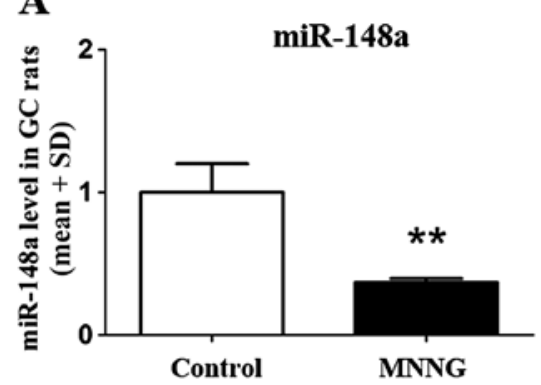

C 2 SMAD2

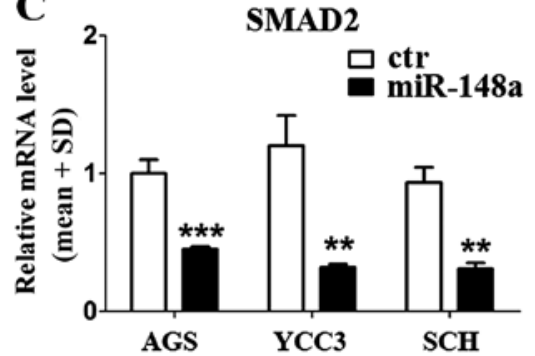

E

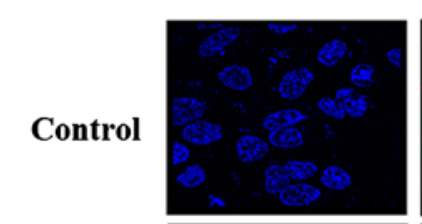

miR-148a
B

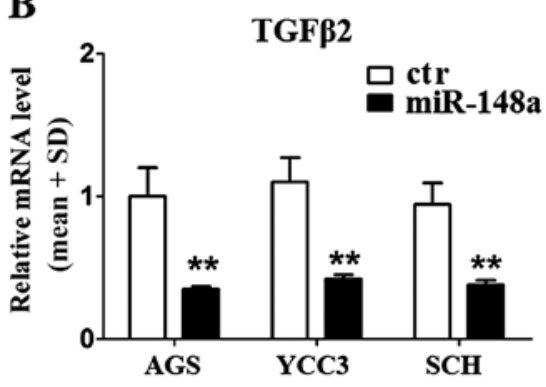

D

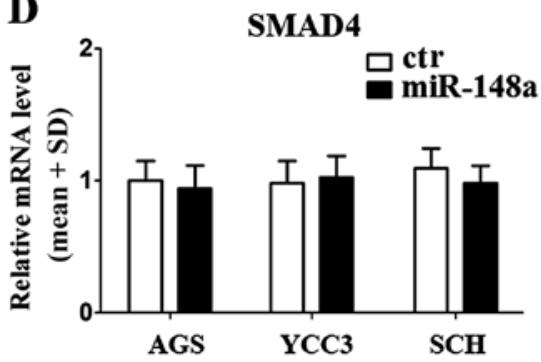

E Hoechst TGFß2
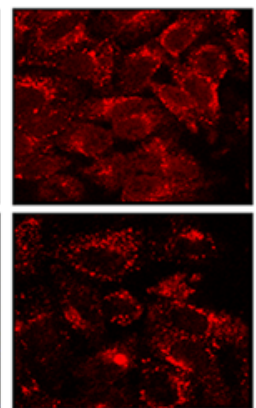

SMAD2

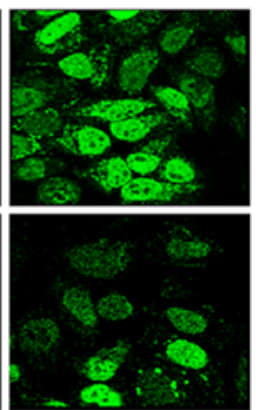

Merge

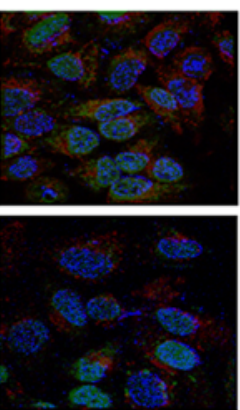

Figure 3. Effects of miR-148a on the expression of TGF 32 and SMAD2 in GC cells. The miR-148a levels in different groups were tested. MNNG significantly reduced miR-148a levels in the GC rat model compared with the control group (A). Overexpressing miR-148a inhibited the mRNA levels of TGF 32 and SMAD2 in GC cells (B and C), but did not affect SMAD4 (D), suggesting that the changes in SMAD4 in MNNG-treated rats were not regulated by miR-148a. Immunofluorescence cytochemistry demonstrates the effects of miR-148a on TGF $\beta 2$ (red) and SMAD2 (green) in GC cells (E). ${ }^{* *}<<0.01$ and ${ }^{* * *}$ p $<0.001$ vs. the control.

with the control group, respectively (Fig. 2B and G). SMAD2 mRNA and protein levels were 1.8- and 2.0-fold higher in the MNNG-treated group compared with the control group, respectively (Fig. 2C and $\mathrm{H}$ ). SMAD4 mRNA and protein levels were 1.3- and 1.5-fold higher in the MNNG-treated group compared with the control group, respectively (Fig. 2E and $\mathrm{J}$ ). However, there were no differences in TGF $\alpha$ and SMAD3 in either the mRNA or protein level (Fig. 2A, D, F and I). These data suggested that MNNG could upregulate TGF 32 , SMAD2 and SMAD4, subsequently leading to GC. However, the results demonstrated that TGF $\alpha$ and SMAD3 were not involved in the mechanism of MNNG initiated GC in the rat model.

miR-148a decreases the expression of TGF $\beta 2$ and SMAD2 in $G C$ cells. To verify whether miR-148a regulated the expression of TGF 32 , SMAD2, and SMAD4, we used a QPCR assay to quantify the level of miR-148a in the GC rat model. The results showed that miR-148a was inhibited significantly in MNNG-treated rats compared with normal rats (reduced 63\%) (Fig. 3A). The data suggested that miR-148a might be involved in the occurrence and development of GC via MNNG treatment. Furthermore, we constructed a primary miR-148a expression plasmid and transfected it into GC cells (AGS, YCC3, and SCH) and verified the mRNA levels of TGF $\beta 2$, SMAD2, and SMAD4. The results demonstrated that the mRNA levels for both TGF $\beta 2$ and SMAD2 were reduced in all three GC cell lines (Fig. 3B and C), but SMAD4 mRNA levels were not affected by miR-148a (Fig. 3D). These data suggested that miR-148a could regulate the mRNA levels of TGF $\beta 2$ and SMAD2, but not SMAD4. We used immunofluorescence cytochemistry to demonstrate the effects of miR-148a overexpression in AGS cells. The results confirmed that miR-148a could inhibit the expression of TGF $\beta 2$ and SMAD2 (Fig. 3E). As shown in Fig. 3E, the expression of TGF $\beta 2$ (red) was predominantly located in the cytoplasm, and SMAD2 was expressed in both the cytoplasm and nucleus (green). Overexpression of miR-148a inhibited the levels of TGF 32 and SMAD2 significantly (Fig. 3E, down).

miR-148a binds to TGF $\beta 2$ - and SMAD2-3'UTRs in GC cells. To verify the regulation mechanism of TGF $\beta 2$ and SMAD2 by miR-148a, we analyzed the 3'-UTR sequences of the TGF 32 and $S M A D 2$ genes and performed luciferase assays to confirm 


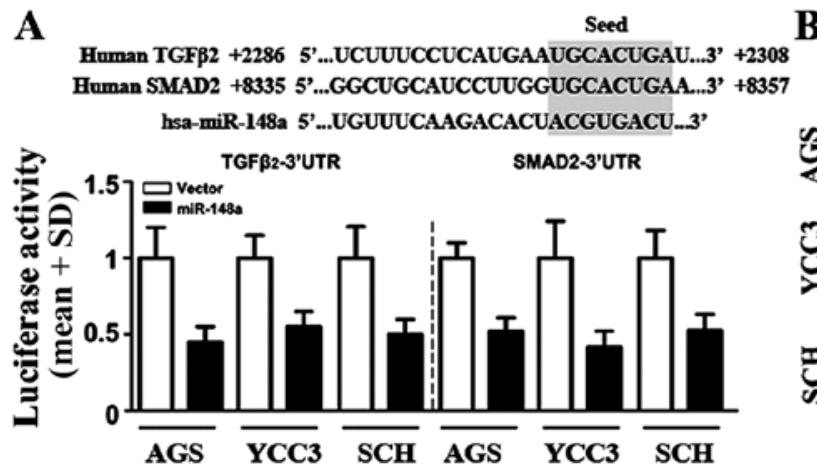

\section{B}
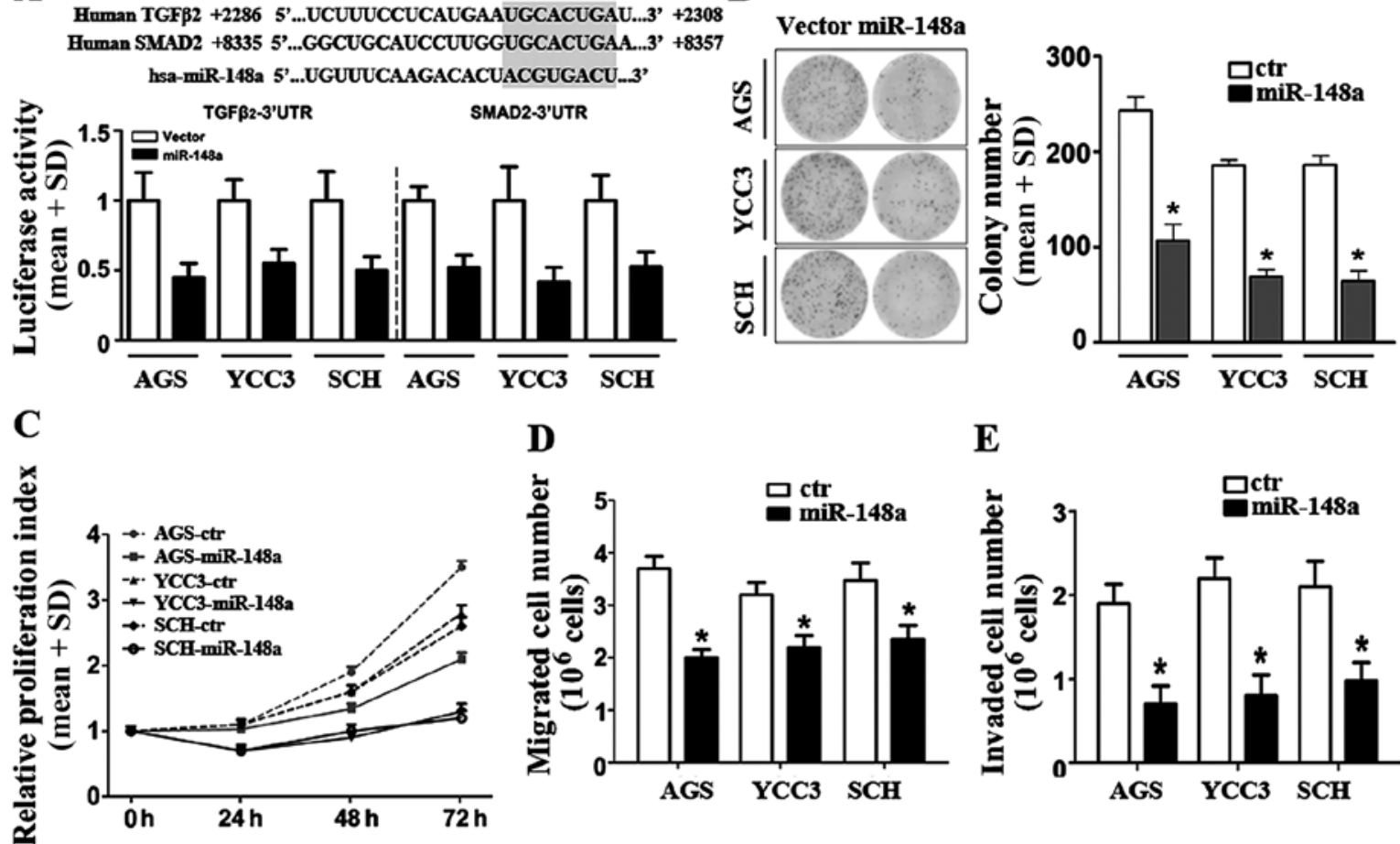

D

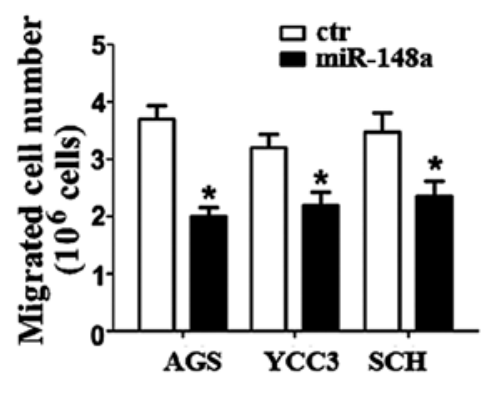

$\mathbf{E}$

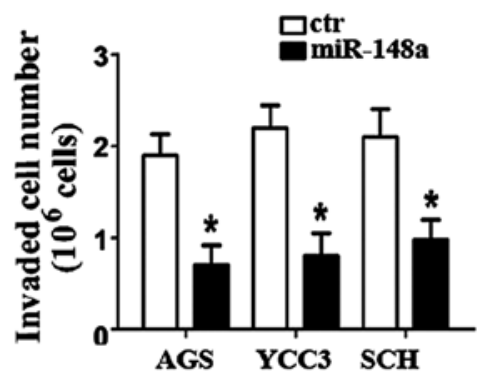

Figure 4. miR-148a expression modulates multiple pro-oncogenic traits in GC cells. The co-transfection of miR-148a decreased the luciferase activity in cells transfected with 3'-untranslated regions (3'-UTRs) of the TGF 22 and SMAD2 genes located at $+2,286$ to $+2,308$, and $+8,335$ to $+8,357$, respectively (A). The predicted target sequences of miR-148a located on the 3'-UTRs of human TGF 32 and SMAD2 genes (upper) (A). Representative micrographs (left) and quantification (right) of crystal violet-stained cell colonies (B). miR-148a expression suppresses cellular proliferation in GC cell lines (C). miR-148a-transfected cell lines were assessed for cell proliferation at 24, 48 and $72 \mathrm{~h}$ post-transfection. Triplicate experiments were conducted for each set. (D and E) miR-148a reduces motility and invasiveness of GC cells. ${ }^{*} \mathrm{p}<0.05,{ }^{* *} \mathrm{p}<0.01 \mathrm{vs}$. the control.

whether miR-148a could bind to the TGF 32 and $S M A D 2$ genes. The luciferase activities in AGS, YCC3, and SCH cells transfected with the TGF 32 - and SMAD2-3'-UTR reporter plasmids were inhibited following co-transfection with a miR-148a plasmid (Fig. 4A). These data suggested that the binding sites of miR-148a in both the TGF 32 - and SMAD23'UTRs were functional.

miR-148a reduces the proliferation, migration, and invasion of GC cells. To investigate the functional significance of miR148a downregulation in GC cells, we selected three GC cell lines (AGS, YCC3, and SCH). The miR-148a primary plasmid was constructed and transfected into these cell lines, and the miR-148a expression levels in these cells were confirmed by qRT-PCR (data not shown). To investigate the biological effect of miR-148a inhibition on gastric cancer progression, the AGS, YCC3, and SCH gastric cancer cell lines were transfected with miR-148a. Colony formation assay showed that miR-148a decreased the rate of cell proliferation significantly (Fig. 4B).

Then, we compared the cell proliferation rates of the control- and miR-148a-transfected cells at various time points. In all three cell lines, the growth of miR-148a-transfected cells was reduced significantly compared to cells transfected with negative-control miRs (Fig. 4C). These results suggested that miR-148a overexpression was sufficient to inhibit cellular proliferation in GC cells. To assess the effects of miR-148a on GC migration and invasion, we tested the three cell lines that stably expressed miR-148a or empty vectors. All cell expressing vector controls migrated robustly in the Transwell assays (Fig. 4D), whereas those overexpressing miR-148a exhibited a significant reduction in migration capacity in GC cells (reduced approximately 46, 32 and 33\%, respectively). Similarly, in the invasion assays, overexpression of miR-148a exhibited inhibition of the invasion capacity compared with controls in three GC cell lines (the inhibition rates were 63\% in AGS, 64\% in YCC3, and 53\% in SCH cells) (Fig. 4E). Taken collectively, these results indicated that miR-148a overexpression was sufficient to suppress several pro-oncogenic traits in vitro, consistent with miR-148a playing a tumorsuppressive role in GC cells.

miR-148a inhibits GC development by inhibiting TGF $\beta 2$ and $S M A D 2$. To further investigate the function of miR-148a in a mouse GC model, BALB/c nude mice were given subcutaneous injections withBGC-823-miR-148a cells or BGC-vector cells. The tumor volumes were calculated every three days. The results demonstrated that miR-148a could decrease BCG-823 growth in vivo (Fig. 5A). The Ki-67 protein is a cellular marker for proliferation. In this study, flow cytometry results indicated that the percentage of Ki-67 in BGC-823-miR-148a tumor tissues was lower than that in BGC-823-vector (Fig. 5B and $\mathrm{C}$ ). In the gastric tumor tissues, TGF $\beta 2$ and SMAD2 expression levels were determined by qRT-PCR. In BGC-miR148a, TGF 32 and SMAD2 expression levels were much lower than in BCG-vector cells (Fig. 5D). These results suggested that miR-148a could efficiently reduce gastric cancer proliferation and Ki-67 expression was reduced in BGC-823-miR-148a cells (Fig. 5A-C). miR-148a also inhibited the expression of 
A

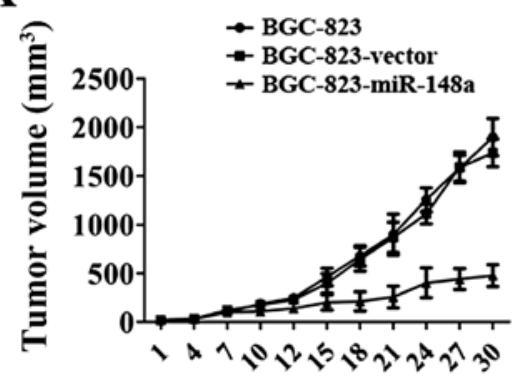

Days after inoculation of tumors cells

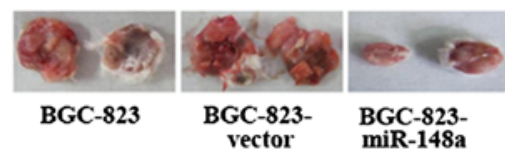

$\mathbf{C}$

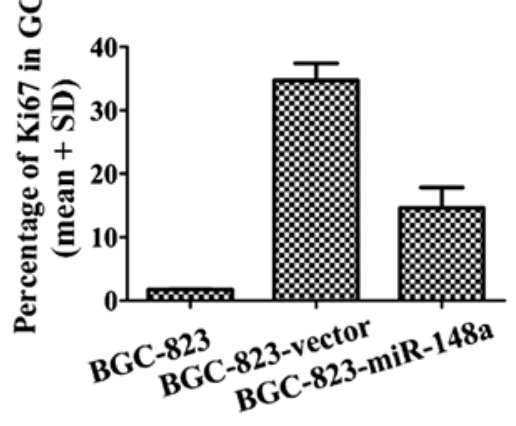

B - Isotype: $1.4 \%$

- BGC-823-miR-148a: $17.8 \%$

- BGC-823-vector: $39.6 \%$

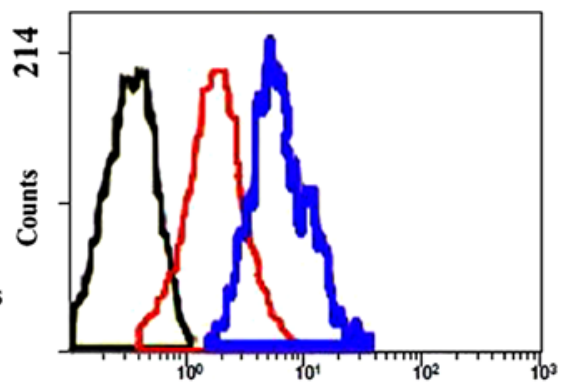

APC-anti Ki67

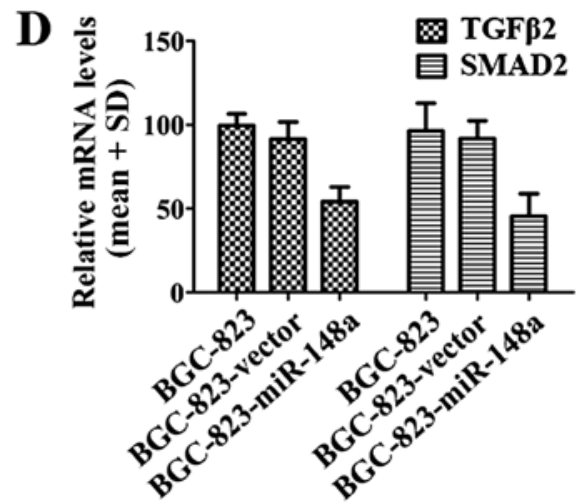

Figure 5. miR-148a inhibited GC cells in vivo. Volumes of BGC-823 tumors in vivo were detected every three days with or without miR-148a transfection ( $\mathrm{n}=6$, two of each group are representative tumors of six) (A). Cell proliferation of BGC-823-miR-148a/BGC-823-vector in tumor tissue was determined with APC-Ki67 mAb using flow cytometry (B). Percentage of Ki67 in GC tissue from GC mouse model (n=6) (C). Expression of TGF 32 and SMAD2 in GC cells with BGC-823-miR-148a/BGC-823-vector from tumor tissue (D).

TGF 32 and SMAD2 (Fig. 5D). These results suggested that miR-148a inhibited GC development by inhibiting TGF $\beta 2$ and SMAD2.

\section{Discussion}

In this study, we determined the changes in miR-148a, TGF $\alpha$, TGF 32 , SMAD2, SMAD3, and SMAD4 levels in MNNGinitiated gastric carcinoma in Wistar rats, and examined the role of miR-148a in inhibiting the expression of TGF $\beta 2$ and SMAD2 in GC cell lines. We found that miR-148a could inhibit cellular proliferation, migration, and invasion in GC cells. MNNG-induced GC is a well-established animal model for gastric carcinogenesis $(26,27)$. GC is one of the most devastating cancers in humans and causes a particularly high mortality worldwide (28). Achieving a better understanding of the molecular mechanisms associated with GC carcinogenesis might identify new diagnostic and treatment strategies for this disease. Numerous genes have been established to be involved in this disease, including tumor-suppressor genes and oncogenes (p53, $\beta$-catenin), gene amplifications and deletions (c-Meta, ERBB2), and anti-inflammatory factors (TGF $\alpha, T G F \beta 2)(29,30)$, but the function of miRs in this disease remains unclear.

We found that, compared with the control group, the mRNA and protein levels of TGF $\beta 2$, SMAD2, and SMAD4 were increased significantly in MNNG-initiated GC rats, but miR-148a levels were reduced. However, the TGF $\alpha$ and SMAD3 expression levels were not influenced by MNNG. Previously, studies have shown that SMAD2 is the primary intracellular signaling pathway downstream of TGF- $\beta$ (29). TGF- $\beta$ can act as an oncogenic factor, and it is involved in proliferation, angiogenesis, invasion, and metastasis (31). In glioma patients, high TGF $\beta$-SMAD activity was present in aggressive, highly proliferative gliomas, and it conferred poor prognosis (32). Another research group reported that activation of SMAD2 could induce the migration of mouse squamous carcinoma cells (33). Overexpression of SMAD2 was also suggested to be associated with metastasis and was correlated with poor prognosis of GCs, especially diffuse-type gastric carcinomas (34). In our study, TGF 32 and SMAD2 expression levels were both elevated in MNNG-treated rats, suggesting that TGF $\beta 2$ and SMAD2 were promising target genes that were related to metastasis in GC cells.

Recently, evidence has convincingly shown that miRs play an important role in many human cancers $(8,14)$. A previous miR profiling study that used tumor and normal GC tissues found that approximately $80 \mathrm{miRs}$ exhibited expression imbalance. Among them, the tumor-suppressor miR-148a was one of the most significantly downregulated miRNAs in GC cell lines and GC tissues from GC patients compared with the adjacent normal gastric tissues (35). 
However, the downstream targets of this miRNA are still unclear. We identified the role of miR-148a in regulating the expression of TGF 32 , SMAD2, and SMAD4. The results indicated that overexpression of miR-148a could reduce the mRNA levels of TGF $\beta 2$ and SMAD2 significantly, but not SMAD4. These results were consistent with the immunofluorescence cytochemistry data. Furthermore, we assayed luciferase activity using human GC cells and found that overexpression of miR-148a could inhibit the activities of the TGF $\beta 2$ - and SMAD2-3'UTRs. These data suggested that the binding sites of miR-148a were functional. In this study, we demonstrated the effects of miR-148a on proliferation, migration, and invasion in GC cells. The growth of miR148a-transfected cells was reduced significantly compared with cells that were transfected with negative-control miRs. Simultaneously, the miR-148a-transfected cells exhibited the capacity for migration and invasion compared with the controls in three GC cell lines. In vivo, miR-148a also displayed an inhibited function to GC, which suggested that miR-148a inhibited GC development via inhibiting TGF $\beta 2$ and SMAD2.

In conclusion, to our knowledge, our study is the first to functionally explore the role of miR-148a in GC development and progression. Our data suggests that miR-148a may act as a novel tumor-suppressor miR in GC. In addition to providing the probable mechanism involved in the regulation of the expression of TGF $\beta 2$ and SMAD2, our findings may also have translational relevance as miRNAs have also been proposed to be potential therapeutic candidates. By understanding the mechanism and function of miR-148a as a tumor suppressor, it may eventually be possible to develop miR-148a as a therapeutic agent in GC treatment.

\section{Acknowledgements}

This work was supported by the Key Project of the National Natural Science Foundation of China (81230031/H18), the National Science Foundation of China (61272274), and the Hubei Province's Outstanding Medical Academic Leader Program.

\section{References}

1. Jemal A, Bray F, Center MM, Ferlay J, Ward E and Forman D: Global cancer statistics. CA Cancer J Clin 61: 69-90, 2011.

2. Ferlay J, Soerjomataram I, Dikshit R, Eser S, Mathers C, Rebelo M, Parkin DM, Forman D and Bray F: Cancer incidence and mortality worldwide: Sources, methods and major patterns in GLOBOCAN 2012. Int J Cancer 136: E359-E386, 2015.

3. Uemura N, Okamoto S, Yamamoto S, Matsumura N, Yamaguchi S, Yamakido M, Taniyama K, Sasaki N and Schlemper RJ: Helicobacter pylori infection and the development of gastric cancer. N Engl J Med 345: 784-789, 2001.

4. Li G, Wulan H, Song Z, Paik PA, Tsao ML, Goodman GM, MacEachern PT, Downey RS, Jankowska AJ, Rabinowitz YM, et al: Regulatory B cell function is suppressed by smoking and obesity in $H$. pylori-infected subjects and is correlated with elevated risk of gastric cancer. PLoS One 10: e0134591, 2015.

5. Garzon R, Calin GA and Croce CM: MicroRNAs in cancer. Annu Rev Med 60: 167-179, 2009.

6. Bass AJ, Thorsson V, Shmulevich I, Reynolds SM, Miller M, Bernard B, Hinoue T, Laird PW, Curtis C, Shen H, et al; Cancer Genome Atlas Research Network: Comprehensive molecular characterization of gastric adenocarcinoma. Nature 513: 202-209, 2014.
7. Tan IB, Ivanova T, Lim KH, Ong CW, Deng N, Lee J, Tan SH, $\mathrm{Wu}$ J, Lee $\mathrm{MH}$, Ooi CH, et al: Intrinsic subtypes of gastric cancer, based on gene expression pattern, predict survival and respond differently to chemotherapy. Gastroenterology 141: 476-485, 485.e1-485.e11, 2011.

8. Lei Z, Tan IB, Das K, Deng N, Zouridis H, Pattison S, Chua C, Feng $\mathrm{Z}$, Guan YK, Ooi CH, et al: Identification of molecular subtypes of gastric cancer with different responses to PI3-kinase inhibitors and 5-fluorouracil. Gastroenterology 145: 554-565, 2013.

9. Wang K, Kan J, Yuen ST, Shi ST, Chu KM, Law S, Chan TL, Kan Z, Chan AS, Tsui WY, et al: Exome sequencing identifies frequent mutation of ARID1A in molecular subtypes of gastric cancer. Nat Genet 43: 1219-1223, 2011.

10. Lin S and Gregory RI: MicroRNA biogenesis pathways in cancer. Nat Rev Cancer 15: 321-333, 2015.

11. Bartel DP: MicroRNAs: Genomics, biogenesis, mechanism, and function. Cell 116: 281-297, 2004.

12. Bartel DP: MicroRNAs: Target recognition and regulatory functions. Cell 136: 215-233, 2009.

13. Hwang HW and Mendell JT: MicroRNAs in cell proliferation, cell death, and tumorigenesis. Br J Cancer 96 (Suppl): R40-R44, 2007.

14. Kent OA and Mendell JT: A small piece in the cancer puzzle: microRNAs as tumor suppressors and oncogenes. Oncogene 25: 6188-6196, 2006.

15. Calin GA and Croce CM: MicroRNA signatures in human cancers. Nat Rev Cancer 6: 857-866, 2006.

16. Gaur A, Jewell DA, Liang Y, Ridzon D, Moore JH, Chen C, Ambros VR and Israel MA: Characterization of microRNA expression levels and their biological correlates in human cancer cell lines. Cancer Res 67: 2456-2468, 2007.

17. Ueda T, Volinia S, Okumura H, Shimizu M, Taccioli C, Rossi S, Alder H, Liu CG, Oue N, Yasui W, et al: Relation between microRNA expression and progression and prognosis of gastric cancer: A microRNA expression analysis. Lancet Oncol 11: 136-146, 2010.

18. Li X, Zhang Y, Zhang Y, Ding J, Wu K and Fan D: Survival prediction of gastric cancer by a seven-microRNA signature. Gut 59: 579-585, 2010.

19. Petrocca F, Visone R, Onelli MR, Shah MH, Nicoloso MS, de Martino I, Iliopoulos D, Pilozzi E, Liu CG, Negrini M, et al: E2F1-regulated microRNAs impair TGFbeta-dependent cellcycle arrest and apoptosis in gastric cancer. Cancer Cell 13: 272-286, 2008

20. Bandres E, Bitarte N, Arias F, Agorreta J, Fortes P, Agirre X, Zarate R, Diaz-Gonzalez JA, Ramirez N, Sola JJ, et al: microRNA-451 regulates macrophage migration inhibitory factor production and proliferation of gastrointestinal cancer cells. Clin Cancer Res 15: 2281-2290, 2009.

21. Oh HK, Tan AL, Das K, Ooi CH, Deng NT, Tan IB, Beillard E, Lee J, Ramnarayanan K, Rha SY, et al: Genomic loss of miR-486 regulates tumor progression and the OLFM4 antiapoptotic factor in gastric cancer. Clin Cancer Res 17: 2657-2667, 2011.

22. Carvalho J, van Grieken NC, Pereira PM, Sousa S, Tijssen M, Buffart TE, Diosdado B, Grabsch H, Santos MA, Meijer G, et al: Lack of microRNA-101 causes E-cadherin functional deregulation through EZH2 up-regulation in intestinal gastric cancer. J Pathol 228: 31-44, 2012

23. Chen Z, Saad R, Jia P, Peng D, Zhu S, Washington MK, Zhao Z, $\mathrm{Xu} \mathrm{Z}$ and El-Rifai W: Gastric adenocarcinoma has a unique microRNA signature not present in esophageal adenocarcinoma. Cancer 119: 1985-1993, 2013.

24. Zheng G, Xiong Y, Xu W, Wang Y, Chen F, Wang Z and Yan Z: A two-microRNA signature as a potential biomarker for early gastric cancer. Oncol Lett 7: 679-684, 2014.

25. Sakamoto N, Naito Y, Oue N, Sentani K, Uraoka N, Zarni Oo H, Yanagihara K, Aoyagi K, Sasaki H and Yasui W: MicroRNA-148a is downregulated in gastric cancer, targets MMP7, and indicates tumor invasiveness and poor prognosis. Cancer Sci 105: 236-243, 2014.

26. Yu S, Yang M and Nam KT: Mouse models of gastric carcinogenesis. J Gastric Cancer 14: 67-86, 2014.

27. Yang Q, Jie Z, Ye S, Li Z, Han Z, Wu J, Yang C and Jiang Y: Genetic variations in miR-27a gene decrease mature miR-27a level and reduce gastric cancer susceptibility. Oncogene 33: 193-202, 2014.

28. Ang TL, Khor CJ and Gotoda T: Diagnosis and endoscopic resection of early gastric cancer. Singapore Med J 51: 93-100, 2010. 
29. Li QL, Ito K, Sakakura C, Fukamachi H, Inoue K, Chi XZ, Lee KY, Nomura S, Lee CW, Han SB, et al: Causal relationship between the loss of RUNX3 expression and gastric cancer. Cell 109: 113-124, 2002.

30. Kang SH, Bang YJ, Im YH, Yang HK, Lee DA, Lee HY, Lee HS, Kim NK and Kim SJ: Transcriptional repression of the transforming growth factor-beta type I receptor gene by DNA methylation results in the development of TGF-beta resistance in human gastric cancer. Oncogene 18: 7280-7286, 1999.

31. Derynck R, Akhurst RJ and Balmain A: TGF-beta signaling in tumor suppression and cancer progression. Nat Genet 29: 117-129, 2001.

32. Bruna A, Darken RS, Rojo F, Ocaña A, Peñuelas S, Arias A, Paris R, Tortosa A, Mora J, Baselga J, et al: High TGFbeta-Smad activity confers poor prognosis in glioma patients and promotes cell proliferation depending on the methylation of the PDGF-B gene. Cancer Cell 11: 147-160, 2007.
33. Oft M, Akhurst RJ and Balmain A: Metastasis is driven by sequential elevation of $\mathrm{H}-\mathrm{ras}$ and Smad2 levels. Nat Cell Biol 4: 487-494, 2002

34. Shinto O, Yashiro M, Toyokawa T, Nishii T, Kaizaki R, Matsuzaki T, Noda S, Kubo N, Tanaka H, Doi Y, et al: Phosphorylated smad2 in advanced stage gastric carcinoma. BMC Cancer 10: 652, 2010.

35. Xia J, Guo X, Yan J and Deng K: The role of miR-148a in gastric cancer. J Cancer Res Clin Oncol 140: 1451-1456, 2014. 